\title{
Adaptation of Kasuti Embroidery Motifs for Hand Painted Textile Articles
}

\author{
Renu*, Nisha Arya, Neha Chauhan and Suman Sodhi \\ Department of Textile and Apparel Designing, I.C. College of Home Science, \\ CCSHAU, Hisar, Haryana, India \\ *Corresponding author
}

\begin{tabular}{|c|c|}
\hline & A B S T R A C T \\
\hline & en known as the land that portrays culture and traditional vibrancy \\
\hline & $\begin{array}{l}\text { through its conventional art and craft. Every region in India has its own style and pattern of } \\
\text { art known as folk art. These crafts are not only used for decorating and religious purposes }\end{array}$ \\
\hline $\begin{array}{l}\text { Kasuti embroidery, } \\
\text { Hand painted, } \\
\text { Textile. }\end{array}$ & $\begin{array}{l}\text { but they also accommodate day-to-day needs of the people. Indian embroidery profoundly } \\
\text { expresses the richness of diversity because the art of embroidery is exhibited by Indians }\end{array}$ \\
\hline Article Info & Karnataka that speaks about the people of Karnataka; their traditions, customs and \\
\hline $\begin{array}{l}\text { Accepted: } \\
\text { 04 October } 2017 \\
\text { Available Online: } \\
10 \text { December } 2017\end{array}$ & $\begin{array}{l}\text { kasuti embroidery designs with the help of CAD and applying on textiles through time } \\
\text { saving economical surface embellishment techniques like fabric painting. The concept } \\
\text { behind the theme was to create the new design range by maintaining the ethnic beauty and } \\
\text { originality of traditional art of kasuti embroidery. }\end{array}$ \\
\hline
\end{tabular}

\section{Introduction}

India is a land of rich culture and diverse traditions. India has always been known as the land that portrays culture and traditional vibrancy through its conventional art and craft. Indian arts and crafts encompass various forms such as painting, pottery, home decorations, cloth making, needle crafts, jewellery and so on with exquisite designs and patterns. Every region in India has its own style and pattern of art known as folk art. The folk and tribal arts of India are very ethnic and simple and yet colourful and vibrant enough to speak volumes about the country's rich heritage. Indian arts and crafts have the great potential in the international market because of its traditional aesthetic sensibility and authenticity (Sharma, 2015).
India's long known heritage of art, music, dance, sculpture, architecture, carpentry, metal work, designing, painting and embroidery exemplifies the richness of Indian culture. These crafts are not only used for decorating and religious purposes but they also cater to day-to-day needs of the people. Printing, painting, dyeing, brocading techniques are some of the techniques that have been traditionally used all over the world to decorate textiles, apparels and home furnishing articles for their personal use. Among these, Indian embroidery profoundly expresses the richness of diversity because the art of embroidery is exhibited by Indians who have been living widely region wise (Pandit, 1976). Embroidery is one of the most 
satisfying and interesting art which is gaining more and more popularity day by day as it requires minimum equipment and space (Lehri, 2006).

Each state in India is unique in itself as far as embroidery of its variegated designs is concerned (Namrata, 2006). Kasuti is world famous embroidery of Karnataka state and is famous in many places of Bijapur, Dharwad, Balgaum and Jamakhandi districts.

As an art form, it speaks about the people of Karnataka; their traditions, customs and professions. Its delicate rendition is an outcome of the honest, zealous and innate desire of 'mankind' to practice the beautiful stitches on the articles of everyday use (Bennur and Gavai, 2015).

Due to modernization and changing fashion scenario, demands for new textile designs are increasing day by day. Textile designing is hence emerging as a field full of scope and creativity. Over a period of time it has also increasingly become an intellectual endeavor.

The technique of CAD is a powerful tool for textile designing. It saves time and gives freedom to explore and manipulate design in relatively less time (Rai, 2002).

The rich motifs of the existing art of kasuti embroidery can be adapted into contemporary form to make them suitable for various textile products. This can be done by creating kasuti embroidery designs with the help of CAD and applying on textiles through time saving economical surface embellishment techniques like fabric painting.

Hence, the present study on was conducted to explore the possibility of creating new range of designs by maintaining the ethnic beauty and originality of traditional art of kasuti embroidery.

\section{Materials and Methods}

\section{Collection of motifs}

Motifs of kasuti embroidery were collected from secondary sources like books, magazines, journal and internet. A total of fifty motifs were collected. The collected motifs were categorized in three categories as geometrical, floral, and animal and bird motifs. The categorized motifs were screened into thirty motifs by experts keeping in mind their suitability for fabric painting on selected articles. These three categories included ten motifs each. Thus, a total of thirty motifs were finalized for further research work. The selected motifs were scanned to convert them from print version to digital format and edited with the help of CorelDraw software. The proportion of motifs was changed to make them suitable for hand painting on textile articles.

\section{Selection of motifs}

Thirty motifs were got assessed by experts with the help of developed preferential index. The experts were asked to give their preferences for each motif separately in different categories for its suitability to hand painting. Their preferences were taken on three point continuum scale as most preferred, preferred and least preferred. The weighted mean score of each motif was calculated to give ranks in different categories. A total of fifteen motifs including five top ranked motifs from each category i.e. geometrical, floral and animal and bird motifs were selected to create designs.

\section{Selection of articles}

For selection of articles to be developed for application of adapted motifs of kasuti embroidery through hand painting technique, a list of textile articles under three broad 
heads i.e. apparel, accessories and utility articles and home textiles was prepared and sorted with the help of advisory committee members. Experts were asked to give their preferences for suitable article on three point rating scale i.e., most preferred, preferred and least preferred. The articles were selected on the basis of their weighted mean score according to expert's choices. Two most preferred articles i.e., jacket and file folder were selected for product development and application of kasuti embroidery motifs through hand painting technique.

\section{Results and Discussion}

This section includes the information regarding collection and selection of motifs, preferences for selection of article and design, placement of selected designs and their placements.

\section{Collected kasuti embroidery motifs}

Kasuti embroidery motifs were collected, categorized, screened and selected for creation of designs.

Secondary sources like books, journals, and internet were explored to gather various kasuti embroidery motifs worked on different articles.

The motifs were categorized as geometrical, floral and animal and bird (Naik and Wilson, 2006).

The data presented in figure 1 revealed that out of fifty collected motifs, $18(36 \%)$ were geometrical motifs followed by $18(36 \%)$ floral motifs and 14(28\%) animal and bird motifs. It was observed that these motifs were mainly used on apparel and utility articles.

It was observed that floral and geometrical motifs were more preferred as compared to animal and bird motifs for application on jacket whereas all the three type of designs got equal preference from experts for application on file folder. Geometrical motifs are commonly found in kasuti embroidery especially on apparel but innovative consumers want to try something new. That is why they also preferred floral and animal and bird motifs. It is important for a good designer to create innovative new ideas to satisfy the needs of high end consumers.

According to Gulia (2008) geometrical motifs also dominate in canvas embroidery for adaptation on furnishing and utility articles. Kaur (2015) in a study observed that floral motifs were the most preferred embroidery motifs.

Second preference was given to geometrical motifs and third preferred motifs were bird motifs. Kavita (2016) reported in a study that seventy percent floral and animal and bird motifs were highly preferred by experts for fabric painting.

\section{Preferences of experts for kasuti embroidery motifs for hand painting}

The thirty screened motifs were assessed by experts on the basis of their suitability for hand painting. They were asked to give their preference separately in each category.

The weighted mean scores as per preferences of experts presented in table 1 revealed that motif number 3 amongst geometrical motifs with 2.85 WMS got I ${ }^{\text {st }}$ rank followed by motif number 7 with $2.6 \mathrm{WMS}$ got $\mathrm{II}^{\text {nd }}$ rank, motif number 10 with 2.4 WMS got III $^{\text {rd }}$ rank, motif number 5 with 2.35 WMS got IVth rank and motif number 1 with $2.3 \mathrm{WMS}$ got $\mathrm{V}$ th rank. The other motifs up to $\mathrm{IX}^{\text {th }}$ rank in descending order were motif number 2(2.2), 4(1.7), 6(1.5) and 8(1.45). The geometrical motif number 9 with 1.35 WMS and got $X^{\text {th }}$ rank. 
Fig.1 Collected kasuti embroidery motifs

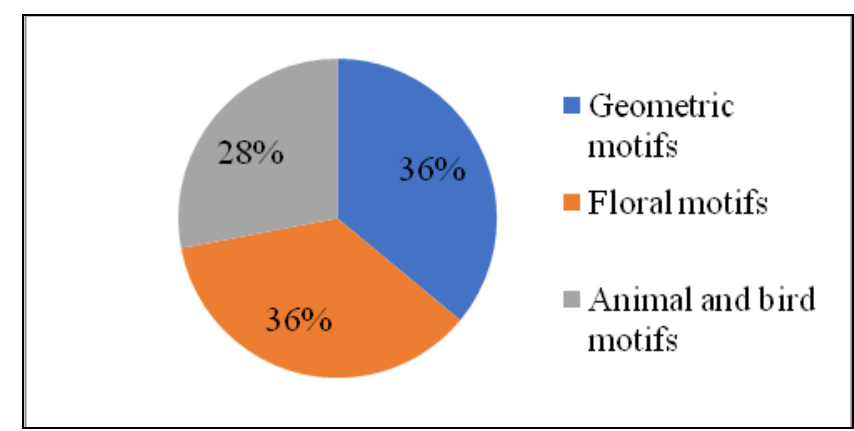

Table.1 Preferences of experts for kasuti embroidery motifs

\begin{tabular}{|c|c|c|c|}
\hline $\begin{array}{c}\text { Sr. No. and } \\
\text { Category }\end{array}$ & Motifs & $\begin{array}{l}\text { WMS } \\
\qquad(\mathbf{n}=\mathbf{2 0})\end{array}$ & Rank \\
\hline \multicolumn{4}{|c|}{ Geometrical Motifs } \\
\hline 1 & & 2.3 & $\mathbf{V}$ \\
\hline 2 & & 2.2 & VI \\
\hline 3 & & 2.85 & $\mathbf{I}$ \\
\hline 4 & & 1.7 & VII \\
\hline 5 & & 2.35 & IV \\
\hline 6 & & 1.5 & VIII \\
\hline 7 & & 2.6 & II \\
\hline 8 & & 1.45 & IX \\
\hline 9 & & 1.35 & $\mathrm{X}$ \\
\hline 10 & & 2.4 & III \\
\hline \multicolumn{4}{|l|}{ Floral Motifs } \\
\hline 11 & & 2.75 & I \\
\hline 12 & & 2.65 & II \\
\hline
\end{tabular}




\begin{tabular}{|c|c|c|c|}
\hline 13 & 28 & 1.5 & IX \\
\hline 14 & & 2.0 & VII \\
\hline 15 & & 2.6 & III \\
\hline 16 & & 2.55 & IV \\
\hline 17 & & 1.6 & VIII \\
\hline 18 & & 2.25 & VI \\
\hline 19 & & 2.35 & $\mathbf{V}$ \\
\hline 20 & & 1.45 & $\mathrm{X}$ \\
\hline \multicolumn{4}{|c|}{ Animal and Birds motifs } \\
\hline 21 & & 1.7 & VII \\
\hline 22 & & 2.2 & $\mathbf{V}$ \\
\hline 23 & 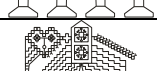 & 2.5 & $\mathbf{I}$ \\
\hline 24 & & 1.5 & IX \\
\hline 25 & & 1.6 & VIII \\
\hline 26 & & 2.4 & II \\
\hline 27 & & 1.45 & $\mathrm{X}$ \\
\hline 28 & & 2.35 & III \\
\hline & & & \\
\hline 29 & & 2 & VI \\
\hline 30 & & 2.25 & IV \\
\hline
\end{tabular}

WMS-Weighted Mean Score, Highly Preferred 2.34-3.00, Preferred 1.67-2.33, Least Preferred 1.00-1.66 
Table.2 Preferences of experts for selection of articles

\begin{tabular}{|c|c|c|c|}
\hline Sr. No & Articles & Experts WMS & Rank \\
\hline \multicolumn{4}{|c|}{ (I) APPAREL } \\
\hline 1 & Kameez & 2.5 & IV \\
\hline 2 & Kurti / kurta & 2.6 & III \\
\hline 3 & Shawl / Stole & 2.0 & XI \\
\hline 4 & Top & 2.1 & $\mathrm{X}$ \\
\hline 5 & Jacket & 2.75 & I \\
\hline 6 & Skirt & 2.3 & VII \\
\hline \multicolumn{4}{|c|}{ (II) HOME TEXTILES } \\
\hline 7 & Bed sheet & 1.45 & XXII \\
\hline 8 & Pillow cover & 1.5 & XXI \\
\hline 9 & Cushion cover & 2.35 & VI \\
\hline 10 & Sofa cover & 1.95 & XII \\
\hline 11 & Dining table cover & 1.55 & $\mathrm{XX}$ \\
\hline 12 & Centre table cover & 2.4 & $\mathrm{~V}$ \\
\hline 13 & Table runner and napkins & 1.35 & XXIV \\
\hline 14 & Computer cover & 1.8 & $\mathrm{XV}$ \\
\hline 15 & T. V. cover & 1.75 & XVI \\
\hline 16 & Wall hanging & 1.7 & XVII \\
\hline \multicolumn{4}{|c|}{ (III) ACCESSORIES/UTILITY ARTICLES } \\
\hline 17 & Caps & 1.9 & XIII \\
\hline 18 & Hand bag & 1.3 & $\mathrm{XXV}$ \\
\hline 19 & Potali/treat bag & 2.25 & VIII \\
\hline 20 & Jewellery pouch/bag & 1.6 & XIX \\
\hline 21 & File folder & 2.70 & II \\
\hline 22 & Pen stand/holder & 1.85 & XIV \\
\hline 23 & Card holder / Magazine & 1.4 & XXIII \\
\hline 24 & Embroidery patches & 1.65 & XVIII \\
\hline 25 & Ready to use borders & 2.2 & IX \\
\hline
\end{tabular}

H.P-Highly Preferred, H-Preferred, L.P-Least Preferred

Motif number 11 amongst floral motifs with 2.75 WMS got $\mathrm{I}^{\mathrm{st}}$ rank followed by motif number 12 with 2.65 WMS got II $^{\text {nd }}$ rank, motif number 15 with 2.6 WMS got III ${ }^{\text {rd }}$ rank, motif number 16 with 2.55 WMS got $\mathrm{IV}^{\text {th }}$ rank and motif number 19 with 2.35 WMS got $\mathrm{V}^{\text {th }}$ rank.

The other motifs up to IX ${ }^{\text {th }}$ rank in descending order were motif number 18(2.25), 14(2.0), 17(1.6) and 13(1.5). The floral motif number 20 was the least preferred motif with 1.45 WMS and got $X^{\text {th }}$ rank.
Motif number 23 amongst animal and bird motifs with 2.5 WMS got $\mathrm{I}^{\text {st }}$ rank by motif number 26 with 2.4 WMS got $\mathrm{II}^{\text {nd }}$ rank, motif number 28 got III $^{\text {rd }}$ rank with WMS 2.35, motif number 30 with 2.25 WMS got IVth rank and motif number 22 with 2.2 WMS got $\mathrm{V}^{\text {th }}$ rank.

The other motifs upto IX ${ }^{\text {th }}$ rank in descending order were motif number 29 (2.0), 21(1.7), 25(1.6) and 24(1.5). The least preferred animal and bird motif was motif number 27 with $1.45 \mathrm{WMS}$ and got $\mathrm{X}^{\text {th }}$ rank. 
It is thus inferred that motif number $3,7,10,5$ and 1 as geometrical motifs, motif number $11,12,15,16$ and 19 as floral motifs and motif number 23, 26, 28,30 and 22 as animal and bird motifs, with $\mathrm{I}^{\text {st }}, \mathrm{II}^{\text {nd }}, \mathrm{III}^{\mathrm{rd}}, \mathrm{IV}^{\text {th }}$ and $\mathrm{V}^{\text {th }}$ ranks respectively in each respective category were selected for creation of designs.

According to Chaudhary and Pant (2014), the animals and birds motif as design adornment on traditional Indian embroideries. The study revealed that varied animals and birds motifs were used in almost all traditional Indian embroideries. Asihene (2004) emphasized that design and ornamentation are usually based on some traditional or ethnic motifs and beliefs and is an important part in the expression of culture.

\section{Preferences of experts for selection of articles}

The data presented in table 2 highlighted the preferences of experts for selection of articles to be hand painted using selected Kasuti embroidery motifs. It was found that jacket got I ${ }^{\text {st }}$ rank with WMS 2.75 followed by file folder got II $^{\text {nd }}$ rank with WMS 2.70 and kurti with 2.6 WMS got III $^{\text {rd }}$ rank. The other articles upto XXIV rank in descending order were kameez (2.5), centre table cover (2.4), cushion cover (2.35), shirt (2.3), potali/treat bag (2.25), ready to use borders (2.2), top (2.1), shawl/stole (2.0), sofa cover (1.95), caps (1.9), pen stand/holder (1.85), computer cover (1.8), T. V. cover (1.75), wall hanging (1.7), embroidery patches (1.65), jewellery pouch/bag (1.6), dining table cover (1.55), pillow cover (1.5), bed sheet (1.45), cardholder / magazine (1.4), table runner and napkins (1.35). The least preferred article was hand bag with 1.3 WMS and got XXV rank.

Jacket and file folder were selected as articles to be hand painted using traditional kasuti embroidery motifs on the basis of experts preferences. Devi (2011) in a study also adapted traditional kantha embroidery motifs for fabric painting on jacket.

Transformation of innovative designs of kasuti embroidery into hand painting has enhanced the range of designing and productivity. Variety of designs can be created through the use of CAD technology employing design tools which aid creativity and make the process more efficient.

\section{References}

Asihene, E. 2004. A Brief History of Art. Woeli Publishing Services. Accra. Pp. 56-58.

Bennur, S. and Gavai, L. 2015. Regional traditional Indian embroidery "Kasuti" key success factors to reach the international markets. Journal of Textile Science \& Engineering. 5: 3.

Chaudhary, B. A. and Pant, S. 2014. Animal and birds as design ornamentation in traditional Indian embroideries. Golden Research Thoughts. 9(3): 7-9.

Devi (2011) Devi, S. 2011. Adaptation of traditional embroidery designs for fabric painting on jacket. Master's Thesis, CCS Haryana Agricultural University, Hisar, India.

Gulia, B.S. 2008. The Traditions of North India. A study on art, architecture and crafts in Haryana, Shubhi Publications, Gurgaon, India. Pp: 2425.

Kaur, A. 2015. Embroidery- An embellishment on women's wear. Research Journal of Family, Community and Consumer Sciences. 3(9): 4-6.

Kavita. 2016. Adaptation of canvas embroidery motifs for fabric painting. Master's Thesis. CCS Haryana Agricultural University, Hisar, India. 
Lehri, R. M. 2006. Indian Embroidery: Ethnic and beyond. Super Book House. Mumbai. Pp: 6-7.

Naik, S. D. and Wilson, J. A. 2006. Surface designing of textile fabrics. New Age International Private Limited, Publishers, New Delhi, India. Pp: 4445.

Namrata, M. 2006. Revival of relic khana material through contemporary designer bed linen. Master's Thesis. University of Agricultural Sciences, Dharwad, Karnataka.
Pandit, S. 1976. Indian Embroidery- Its variegated charms. Jaymudra, Laxmi Eatate, Bahuchargi Road, Baroda:1820.

Rai, I. 2002. Problems and prospects in the $21^{\text {st }}$ century. Books treasure, Jodhpur. Pp: 132-133.

Sharma, E. 2015 Tribal folk arts of India. Journal of International Academic Research for Multidisciplinary. 3(5): 300-308.2015

\section{How to cite this article:}

Renu, Nisha Arya, Neha chauhan and Suman Sodhi. 2017. Adaptation of Kasuti Embroidery Motifs for Hand Painted Textile Articles. Int.J.Curr.Microbiol.App.Sci. 6(12): 73-80. doi: https://doi.org/10.20546/ijcmas.2017.612.009 